\title{
Magnetic Gear Dynamics for Servo Control
}

\author{
R G Montague, C M Bingham (Member, IEEE), K Atallah \\ Department of Electronic and Electrical Engineering, The University of Sheffield, \\ Mappin Street, Sheffield, S1 3JD, United Kingdom \\ c.bingham@sheffield.ac.uk
}

\begin{abstract}
This paper considers the analysis and application of magnetic gearbox and magnetic coupling technologies and issues surrounding their use for motion control servo systems. Analysis of a prototype magnetic gear is used as a basis for demonstrating the underlying nonlinear torque transfer characteristic, nonlinear damping, and 'pole-slipping' when subject to over-torque (overload) conditions. It is also shown how 'pole-slipping' results in consequential loss of control. A theoretical investigation into the suppression of mechanical torsional resonances in transmission systems encompassing these highly-compliant magnetically-coupled components is included, along with experimental results, from a demonstrator drivetrain. The automatic detection of pole-slipping, and recovery scenarios, is also presented.
\end{abstract}

Index Terms - Magnetic gear, coupling, servo control, nonlinear control

\section{NOMENCLATURE}

\begin{tabular}{|c|c|}
\hline$\theta_{M}$ & Motor-side angle \\
\hline$\theta_{L}$ & Load-side angle \\
\hline$\theta_{D}=\theta_{M}-\theta_{L}$ & $\begin{array}{l}\text { Relative Displacement } \\
\text { angle }\end{array}$ \\
\hline$\omega_{R}$ & $\begin{array}{l}\text { Speed Reference (angular } \\
\text { velocity) }\end{array}$ \\
\hline$\omega_{M}=\dot{\theta}_{M}$ & Motor-side angular velocity \\
\hline$\omega_{L}=\dot{\theta}_{L}$ & Load-side angular velocity \\
\hline$T_{M}$ & Motor-side torque \\
\hline$T_{L}$ & $\begin{array}{l}\text { Load-side (disturbance) } \\
\text { torque }\end{array}$ \\
\hline$T_{C}$ & Gear Coupling torque \\
\hline$T_{G}$ & Maximum Gear torque \\
\hline$p$ & Number of pole pairs \\
\hline$\alpha$ & $\begin{array}{l}\text { Percentage of maximum } \\
\text { gear torque in damping } \\
\text { function }\end{array}$ \\
\hline$\beta$ & $\begin{array}{l}\text { Displacement angle for max } \\
\text { damping torque }\end{array}$ \\
\hline$K_{\text {lin }}$ & Linearized spring constant \\
\hline
\end{tabular}

\section{INTRODUCTION}

The perceived future exploitation of magnetic coupling and magnetic gearbox transmission technology is driven by the unique advantages over purely mechanical counterparts viz. reduced maintenance requirements and improved reliability, physical isolation between input and output shafts, elimination of gearbox jamming, and inherent overload protection [1]. While the static torque transmission capability of magnetic couplings/gears can compete with traditional mechanical coupling/gearbox counterparts [2] currently, the primary impediment for their adoption, and the potential safety and economic benefits they can bring to a multitude of application sectors, is the high-compliance characteristics which currently limit their use to systems with relatively low-bandwidth dynamic transients. Moreover, the problem becomes particularly acute for applications where it is prohibitive to use load-side feedback sensors, by virtue of their proximity, reliability, connection, specification, cost or load-side working environment. Applications such as those for aircraft flight control surface actuators, future all-electric automotive power trains and off-shore wind-turbines fall into this category [3], [4], [5]. In addition, research for marine applications, tidal turbines etc, is also being undertaken, as reported in [6], [7].

Although magnetic gearboxes and pseudo-direct drive systems are gaining increasing favor, magnetic coupling counterparts have previously found application in systems that require separation of prime-mover and driven shaft in a noncontact manner viz. clean rooms and particular types of isolated liquid agitation, with torque densities in the range $300-400 \mathrm{kNm} / \mathrm{m}^{3}$.

More recently, Atallah et al [8] reported a new magnetic gear topology employing rare earth magnets that promises high torque densities and high efficiency torque transmission. The proposed magnetic gear consists of a concentric inner, high-speed rotor, and an arrangement of permanent magnets and a low speed outer rotor-see Fig. 1 for instance. 


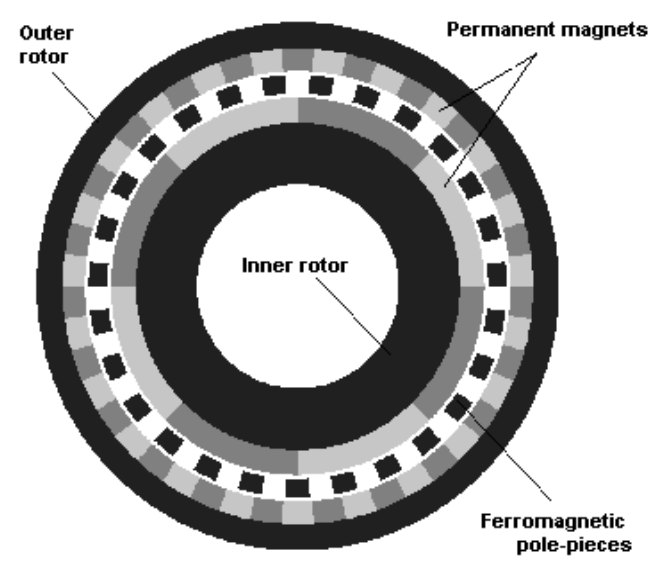

Fig. 1 Schematic of a magnetic gear

Key parameters that dictate the characteristics of the magnetic gear in Fig. 1 are number of high-speed rotor poles (e.g. $\left.P_{h}=4\right)$, the number of low speed rotor poles (e.g. $P_{l}=$ 22 ), and the number of stationary steel pole-pieces (e.g. $\mathrm{n}_{\mathrm{s}}=$ 26). From [8] then, the effective gear ratio $N_{\text {gear }}$ is given by:

$$
N_{\text {gear }}=\frac{p_{h}}{p_{h}-n_{s}}=\frac{4}{4-26}=-\frac{1}{5.5}
$$

The negative polarity indicates that inner and outer rotors contra-rotate. The magnetic gearbox investigated in [9] has a calculated torque-per-unit-volume of more than $100 \mathrm{kNm} / \mathrm{m}^{3}$, in-line with some mechanical counterparts.

Whilst key advantages of magnetic gear/coupling technologies is the 'anti-jamming' and mechanically isolated input-output torque transmission features, the torque vs. mechanical displacement angle characteristic is highly nonlinear. Furthermore, when overload conditions occur, magnetic gears/couplings are subject to over-torque 'poleslipping'. The application of magnetic gear technology for servo-control systems requires greater consideration to be given to the overall dynamic system behavior, and the remedial strategies to be applied in the event of over-torque 'pole-slipping'. An example 'research roadmap' is given in Fig. 2 to highlight pertinent issues.

\section{MAGNETIC GEAR CHARACTERISATION}

To provide a focus to the analysis, an experimental magnetic gear has been constructed with a maximum coupling torque of $\sim 5.7$ N.m. The gear consists of 3-pole-pairs on both the inner and outer rotors, giving a gear ratio of $1: 1$, for simplicity. A schematic of the magnetic gear construction is shown in Fig. 3.

The prototype magnetic gear is assembled into a static/dynamic test-rig consisting of two permanent magnet (PMSM) 4kW machines and two Unidrive inverters under the control of a dSPACE hardware development platform, see Fig. 4(a). In this case, one machine acts as the prime-mover whilst the second imparts a (possibly) dynamic load. By using position control, the displacement position angle between the two sides of the magnetic gear can be controlled, and the static 'holding torque' measured. The resulting torque vs. mechanical displacement angle is shown in Fig. 4(b).

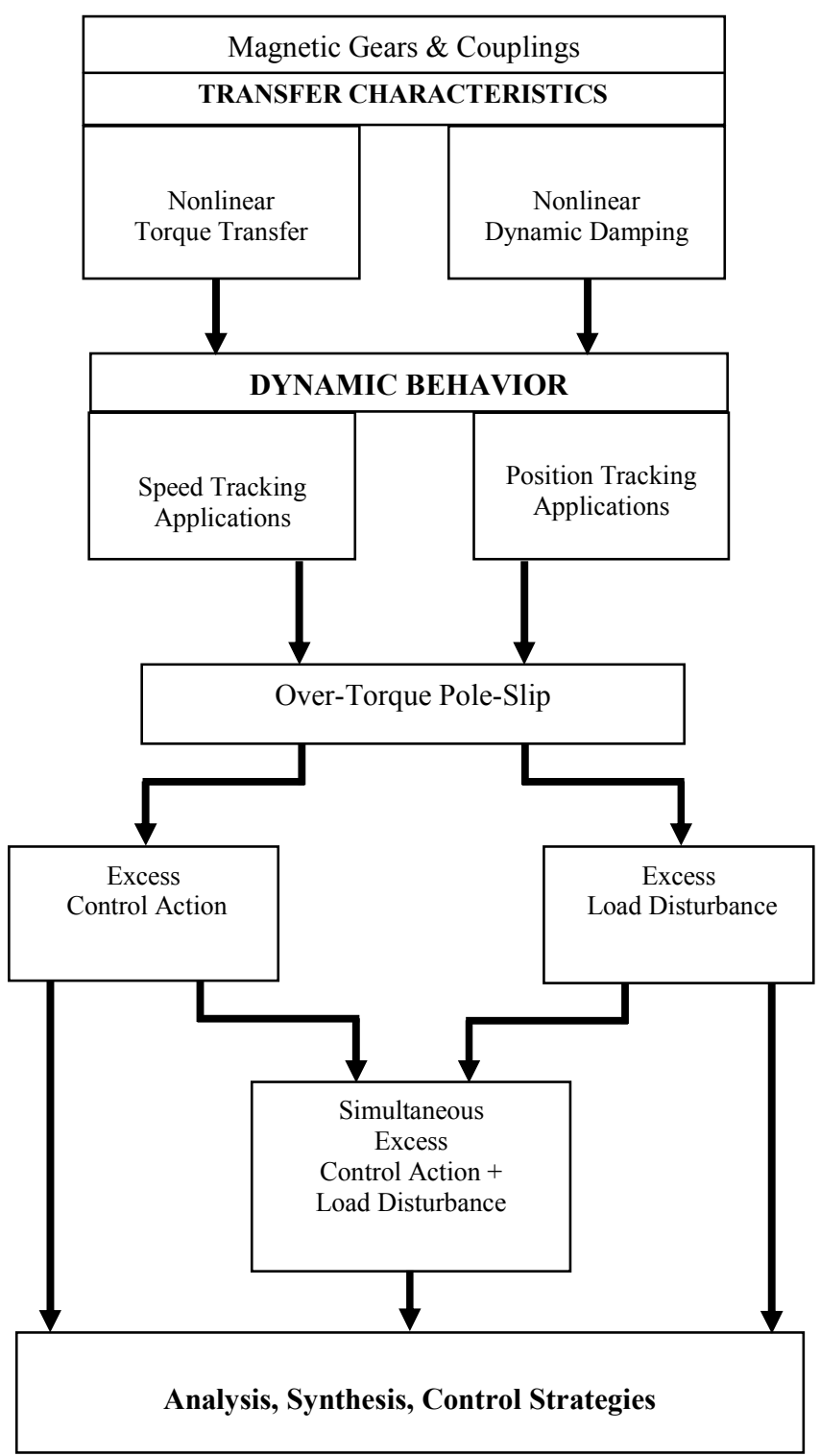

Fig. 2 Magnetic gear 'research roadmap'

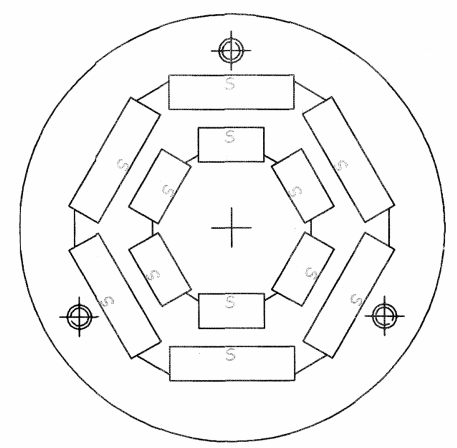

Fig. 3. Schematic of prototype magnetic gear 


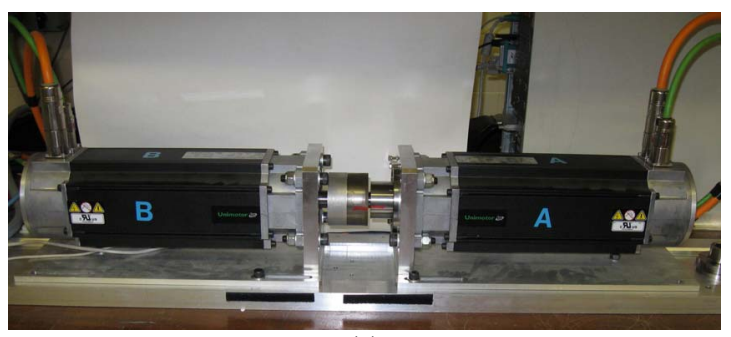

(a)

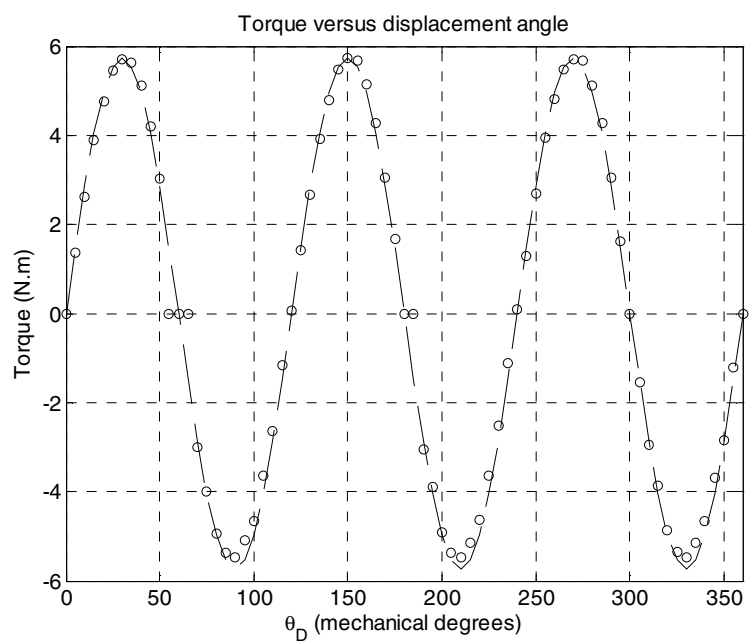

(b)

Fig. 4. Magnetic gear static/dynamic test rig (a) experimental setup (b) Static holding torque vs. displacement angle ' --' theoretical, 'o' experimentally measured

Also shown in Fig. 4(b) is a plot of the theoretically expected torque vs. angle characteristic, described by:

$$
T_{C}=T_{G} \sin \left(p \theta_{D}\right)
$$

where $T_{C}$ represents the magnetic coupling (holding) torque, $T_{G}$, the peak (design) torque, $p$ is the number of pole pairs ( 3 in this case) and $\theta_{D}=\theta_{M}-\theta_{L}$ is the mechanical angular displacement between the motor- and load-side of the magnetic gear, respectively.

What is not obvious from the results of Fig. 4(b) is that the magnetic gear possesses 6 dynamic equilibrium points, 3stable and 3-unstable, as depicted in Fig. 5. Additionally, from a dynamics perspective, an effective 'damping' torque may also be designed into the magnetic gear characteristic. Although from a magnetic analysis perspective the origins are complex and beyond the scope of this paper, the damping that can be magnetically introduced is described by:

$$
B\left(\omega_{D}\right)=2 T_{G} \frac{\alpha \beta \omega_{D}}{\omega_{D}^{2}+\beta^{2}}, \omega_{D}=\left(\omega_{M}-\omega_{L}\right)
$$

where $\alpha$ represents a percentage of the gear's maximum torque capability and $\beta$ represents the relative displacement angle at which maximum damping torque occurs. Example damping characteristics are shown in Fig. 6 for completeness.

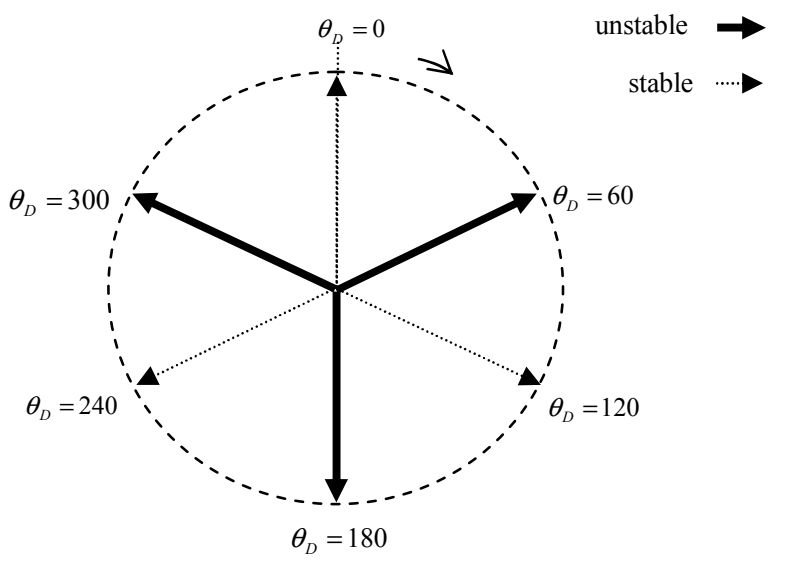

Fig. 5 Equilibrium points for magnetic gear with 3 pole-pairs

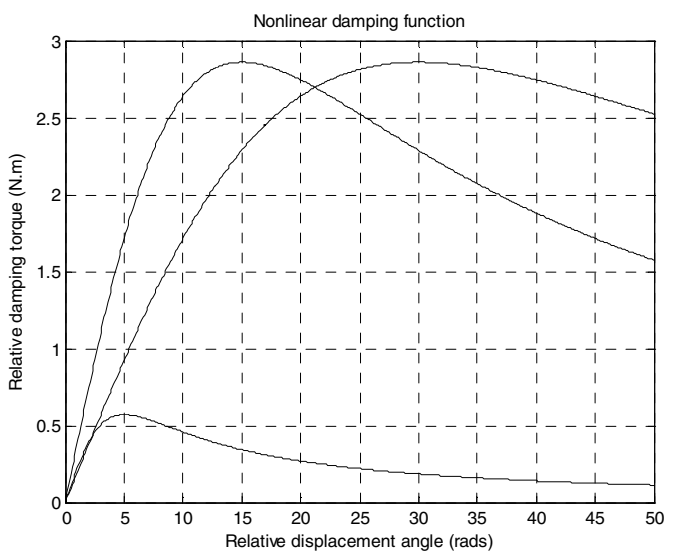

Fig. 6 Damping curves for $\alpha=0.1,0.5, \beta=5,15 \& 30$

\section{MODELLING OF MAGNETIC GEAR}

\section{A. Dual-inertia servo-drive model}

A representation of a two-inertia servo-drive system is shown in Fig. 7. For a conventional system, the interconnecting shaft has a stiffness $K(\mathrm{~N} . \mathrm{m} / \mathrm{rad})$ and is considered to be linear within its operating range. That is,

$$
T_{C}=K \Delta \theta=K\left(\theta_{M}-\theta_{L}\right)
$$

and the developed torque is a linear function of relative angular displacement between the prime-mover (motor in this case) and load.

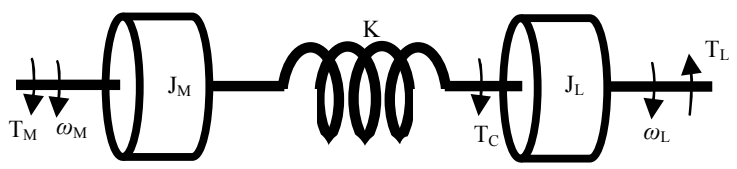

Fig. 7 Dynamic representation of a dual inertia servo-system 
Fig. 8 shows the torque transfer characteristic of an 'ideal' linear torsion spring and the equivalent transfer characteristic of the magnetic gear over the principal displacement angle:

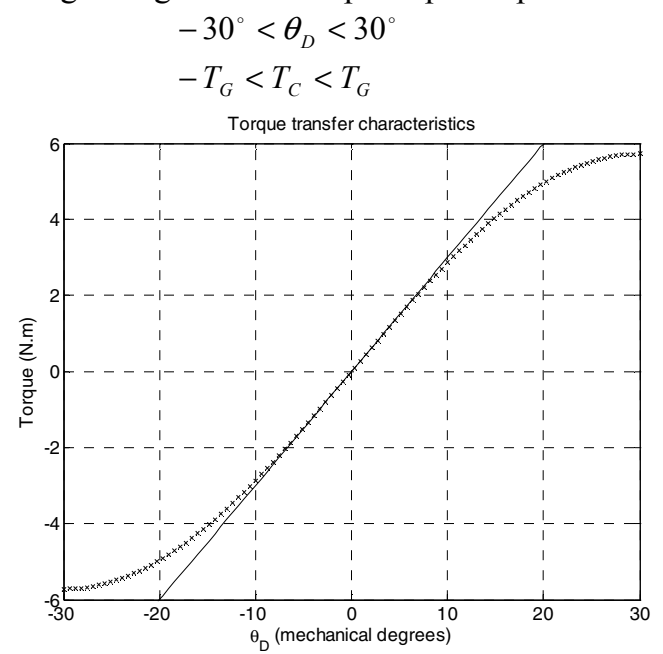

Fig. 8 Static torque transfer characteristics ( $\mathbf{x}$ magnetic gear,-ideal linear spring)

Beyond this range of mechanical displacement angle, the magnetic gear begins pole-slipping, providing effective overtorque protection without jamming. However, just prior to the over-torque condition being reached the magnetic gear behaves as a nonlinear 'soft' torsional spring. When linearized about the origin, the torsional stiffness in this case is given by $K_{\text {lin }}=p T_{G} \approx 17 \mathrm{~N} . \mathrm{m} / \mathrm{rad}$. The linearized transfer characteristic is shown (solid line) in Fig. 8. By way of comparison, a medium torsional stiffness coupling rated at 22 N.m has a torsional stiffness constant of 2500 N.m/rad [10]. Now, from a classical perspective, the linear torsion stiffness constant $K$ of a two-inertia mechanical system with a non-stiff coupling, can be replaced by the nonlinear function $K\left(\theta_{D}\right)$, relating transmitted torque vs. relative angular displacement, between the motor-side and the load-side of the magnetic gear, and $B\left(\omega_{D}\right)$, the nonlinear dynamic damping function. The underlying dynamics are then described by:

$$
\begin{gathered}
J_{M} \frac{d \omega_{M}}{d t}=T_{M}-K\left(\theta_{D}\right)-B\left(\omega_{D}\right) \\
J_{L} \frac{d \omega_{L}}{d t}=K\left(\theta_{D}\right)+B\left(\omega_{D}\right)-T_{L}
\end{gathered}
$$

where

$$
\theta_{D}=\theta_{M}-\theta_{L}, \omega_{D}=\omega_{M}-\omega_{L}
$$

Substituting for the nonlinear torque coupling and nonlinear damping function, from (2) and (3), gives:

$$
\begin{aligned}
& \dot{\omega}_{M}=\frac{T_{M}}{J_{M}}-\frac{T_{G}}{J_{M}} \sin \left(p \theta_{D}\right)-\frac{2 T_{G} \alpha \beta}{J_{M}} \cdot \frac{\omega_{D}}{\omega_{D}{ }^{2}+\beta^{2}} \\
& \dot{\omega}_{L}=\frac{T_{G}}{J_{M}} \sin \left(p \theta_{D}\right)+\frac{2 T_{G} \alpha \beta}{J_{L}} \cdot \frac{\omega_{D}}{\omega_{D}{ }^{2}+\beta^{2}}-\frac{T_{L}}{J_{L}}
\end{aligned}
$$

In terms of the relative mechanical displacement angle,

$$
\begin{aligned}
& \dot{\omega}_{M}-\dot{\omega}_{L}=\ddot{\theta}_{D}=\frac{T_{L}}{J_{L}}+\frac{T_{M}}{J_{M}}-\frac{T_{G}}{J_{E Q}}\left(\sin \left(p \theta_{D}\right)+\frac{2 \alpha \beta \omega_{D}}{\omega_{D}{ }^{2}+\beta^{2}}\right) \\
& J_{E Q}=\frac{J_{M} J_{L}}{J_{M}+J_{L}}
\end{aligned}
$$

or, in state vector notation:

$$
\left[\begin{array}{c}
\dot{\theta}_{D} \\
\dot{\omega}_{D}
\end{array}\right]=\left[\frac{T_{L}}{J_{L}}+\frac{T_{M}}{J_{M}}-\frac{T_{G}}{J_{E Q}}\left(\sin \left(p \theta_{D}\right)+\frac{2 \alpha \beta \omega_{D}}{\omega_{D}^{2}+\beta^{2}}\right)\right]
$$

\section{B. Zero-input 'free response'}

Consider initially the 'free' response of the system with no damping term included, from (8) the equations of motion reduce to:

$$
J_{M} \frac{d \omega_{M}}{d t}=-T_{G} \sin \left(p \theta_{D}\right), J_{L} \frac{d \omega_{L}}{d t}=T_{G} \sin \left(p \theta_{D}\right)
$$

or, in terms of $\theta_{D}=\left(\theta_{M}-\theta_{L}\right)$ :

$$
\ddot{\theta}_{D}=\frac{-T_{G}}{J_{E Q}} \sin \left(p \theta_{D}\right)
$$

giving: $\dot{x}=f(x) \quad$ or $\quad\left[\begin{array}{c}\dot{\theta}_{D} \\ \dot{\omega}_{D}\end{array}\right]=\left[\begin{array}{c}\omega_{D} \\ \frac{-T_{G}}{J_{E Q}} \sin \left(p \theta_{D}\right)\end{array}\right]$

To explore the dynamics, the experimental test-rig has the following parameters:

$$
J_{M}=J_{L}=J=13.8 \cdot 10^{-4} \mathrm{~kg} \cdot \mathrm{m}^{2}, p=3, T_{G}=5.72 \mathrm{~N} . \mathrm{m}
$$

A phase portrait of the dynamics of the system (13) is shown in Fig. 9, where the equilibrium points can now clearly be seen.

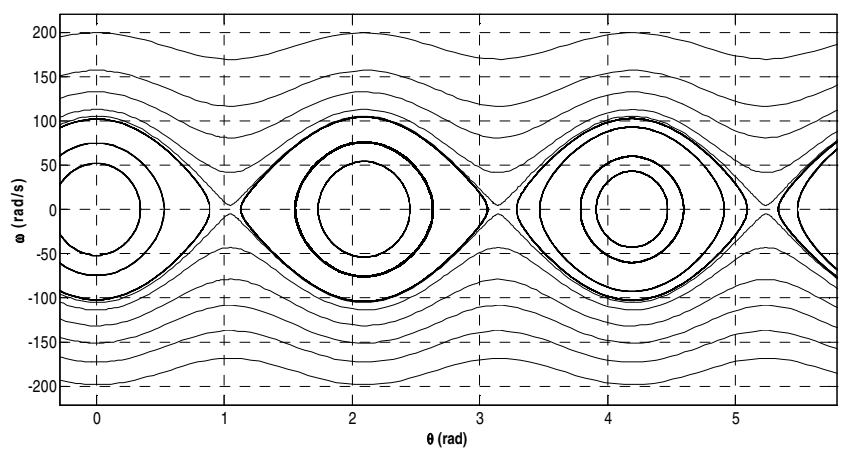

Fig. 9 Phase portrait of un-damped free system

Notably, the dynamics are consistent with those of the 'free un-damped pendulum problem' [11].

C. Zero-input 'free response' with nonlinear damping $B\left(\omega_{D}\right)$ With the inclusion of damping torque, (10) becomes: 


$$
\left[\begin{array}{c}
\dot{\theta}_{D} \\
\dot{\omega}_{D}
\end{array}\right]=\left[\begin{array}{c}
\omega_{D} \\
J \\
\frac{-2 T_{G}}{J}\left(\sin \left(p \theta_{D}\right)+\frac{2 \alpha \beta \omega_{D}}{\omega_{D}{ }^{2}+\beta^{2}}\right)
\end{array}\right]
$$

and the resulting phase portrait is given in Fig. 10.

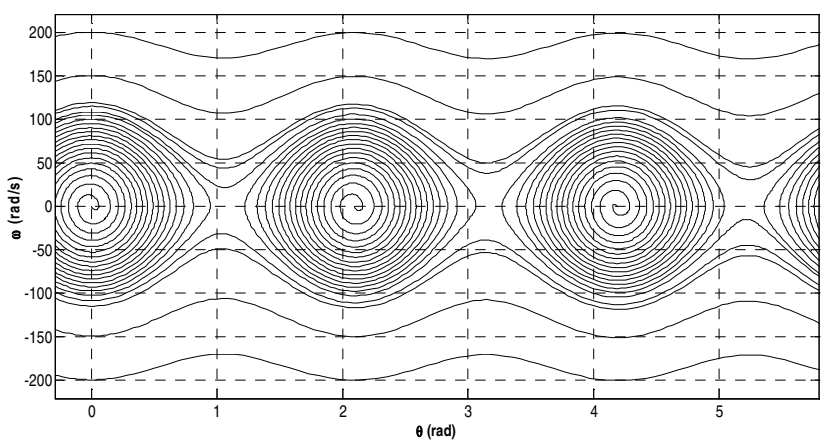

Fig. 10 Phase portrait of damped system with $\alpha=0.1, \beta=5$

\section{EXPERIMENTAL RESULTS}

Whilst 'stiff' torque transmission systems make mechanical power transfer relatively straightforward to control, significant complication and dynamic degradation occurs when shaft compliance is present, leading to under-damped load-side behavior and, in some instances, catastrophic failure of connecting shafts or mechanical gearboxes. Although catastrophic failure conditions are ameliorated when using magnetic gearboxes and couplings, the 'low stiffness' problem is exacerbated by virtue of the nonlinear characteristics of magnetic gears and the over-torque 'pole-slipping' problem. By way of example, Fig. 11 shows results from a $1500 \mathrm{rpm}$ step demand speed input under an optimized controller that has been designed based on minimizing the ITAE metric for an ideal linear shaft. Despite the low stiffness of the magnetic gear, excellent load rejection is obtained with the ITAEoptimised PI controller.
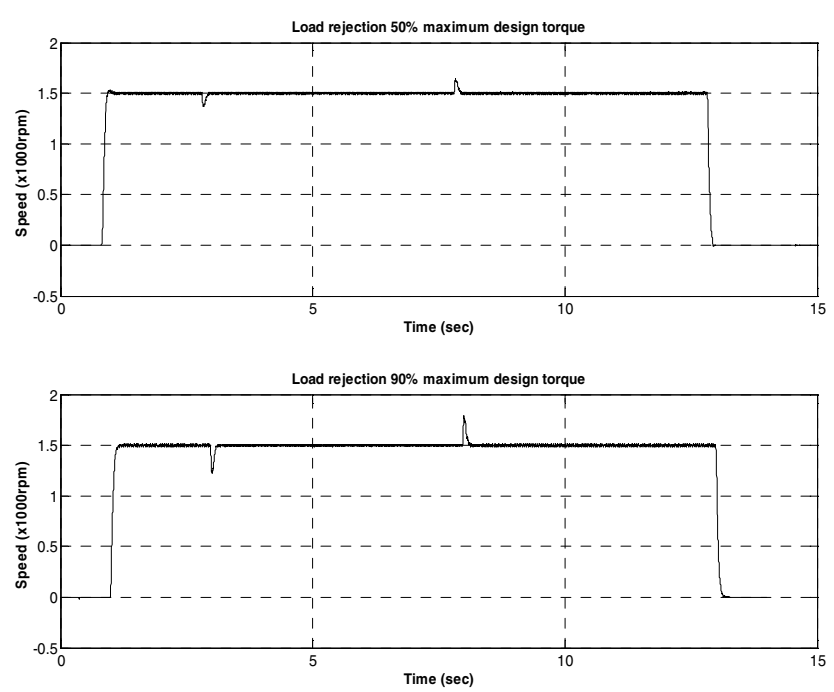

Fig. 11 Load rejection for $50 \%$ and $90 \%$ maximum design torque with optimized ITAE controller
To investigate the effects of 'pole-slipping', the experimental system is subject to i) a load torque that is greater than the maximum design torque, $T_{G}$, and ii) excess control torque resulting from 'too aggressive' control action from the prime-mover. Effectively, this induces 'poleslipping' from either side of the magnetic gear-ultimately a combination of the two will also result in 'pole-slipping'. Figs. 12, 13 show measured results from both scenarios.

From Fig. 12, at $t \cong 1.75 \mathrm{~s}$ an over-load torque is applied to the drive-train, causing pole-slipping. Whilst the speed controller on the prime-mover acts to try and maintain the $1000 \mathrm{rpm}$ demanded, an effective zero-mean load speed is seen. From Fig. 2, this represents conditions on the right-hand side of the flow chart, i.e. over-torque pole-slipping due to excess load-side torque. The dual condition is from excessive control action, depicted on the left-hand side of the flowchart, as in Fig. 13.

From a classical perspective, the effect of 'pole-slipping' constitutes a loss of control of the drive train. Consequently, it is necessary to provide 'pole-slip' detection and recovery- if possible!
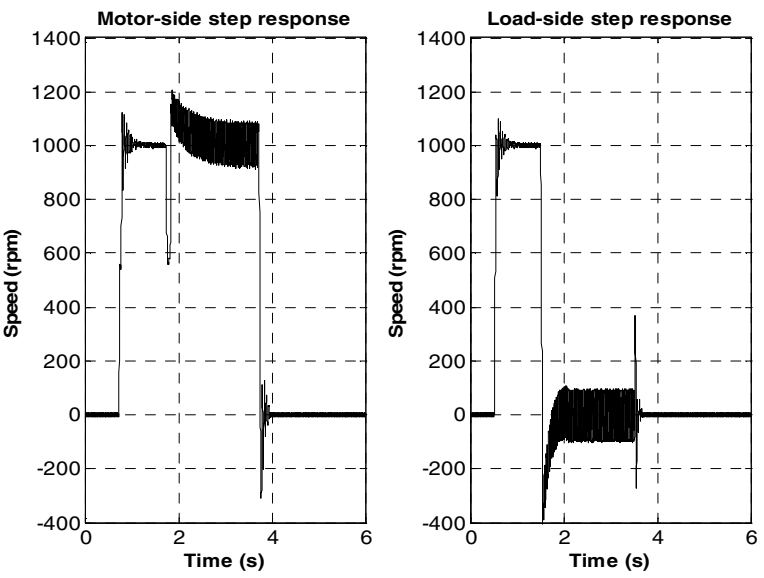

Fig. 12 Excess load-side torque leading to pole-slipping
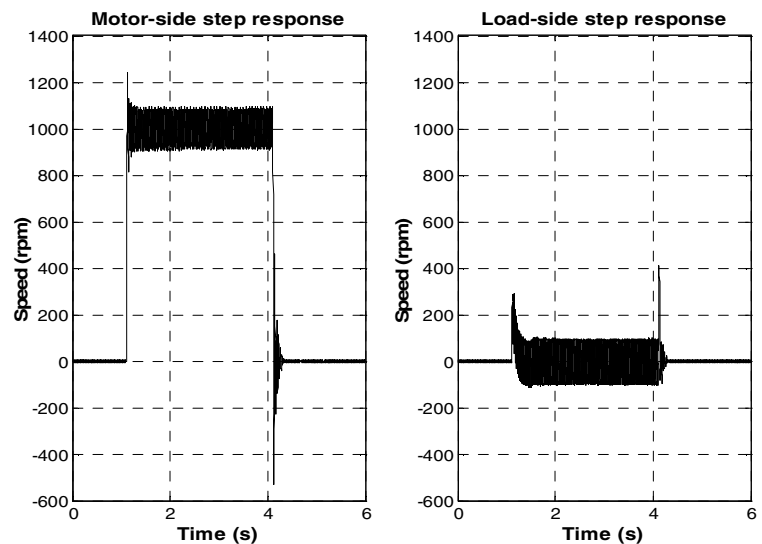

Fig. 13 Excess motor-side torque leading to pole-slipping

Empirical studies have made it apparent that over-torque pole-slipping imposes a modulation onto the speed feedback signal (or error signal). By way of example, the response from 
two transient step demands, $1000 \mathrm{rpm}$ and $1200 \mathrm{rpm}$, are shown in Fig. 14. In each case, the modulating sine wave indicates that the magnetic gearbox has entered a poleslipping regime. Further examination of the power spectral density estimates of the error signals reveals a clearly identifiable signature (in this instance a single sine wave), indicating that an over-torque pole-slipping condition is taking place, Fig. 15.

The presence of a modulating sine wave on the speed feedback signal can be used by the controller to detect gear overload conditions, i.e. in around $50 \mathrm{~ms}$ or less. Consequently, the opportunity then exists for the implementation of remedial action by the controller, allowing the magnetic gear to be 'reset' to normal power delivery within its operating range.

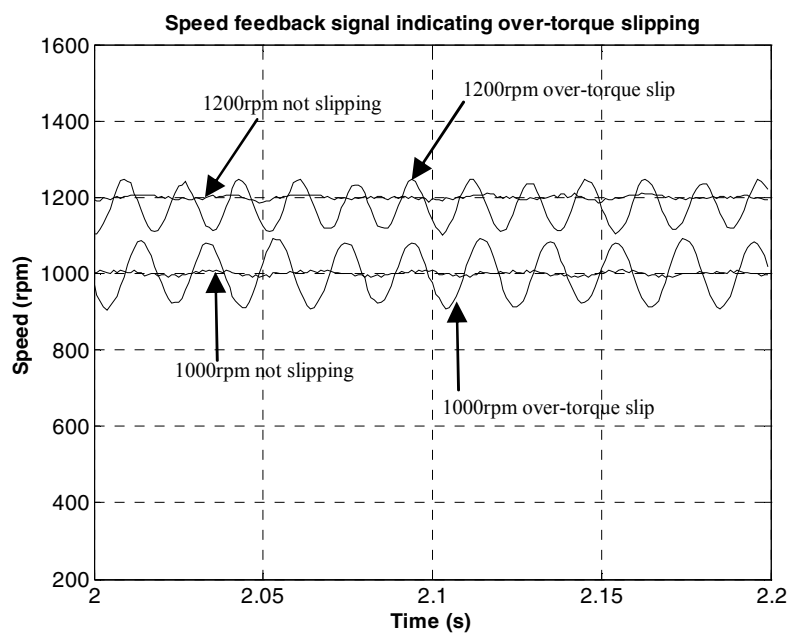

Fig. 14 Sine wave modulation due to over-torque pole-slipping for $1000 \mathrm{rpm}$, $1200 \mathrm{rpm}$ step demands

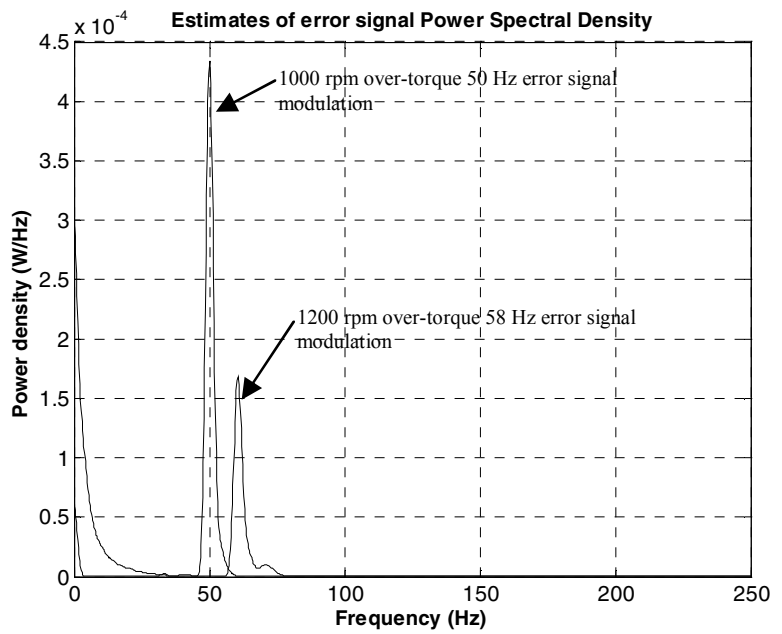

Fig. 15 PSD estimates pole-slipping for $1000 \mathrm{rpm} \& 1200 \mathrm{rpm}$ demands

\section{CONCLUSION}

The paper addresses some of the most important and outstanding issues for the widespread application of magnetic gearboxes and couplings viz. the controlled recovery from overload conditions. Through detailed dynamics analysis and experimental results, the paper shows how complex nonlinear behavior imparted by these systems can be accommodated, thereby opening up their application to the wider field of servo motion control systems, and providing jam-free solutions for mechanical torque transmission.

\section{ACKNOWLEDGMENT}

The work is carried out with the support of the UK EPSRC, by way of the provision of a $\mathrm{PhD}$ studentship.

\section{REFERENCES}

[1] Rizk, J.; Nagrial, M.H.; Hellany, A., "Analysis and design of magnetic torque couplers and magnetic gears," Power Electronics and Motion Control Conference, 2004. IPEMC 2004. The 4th International, vol.3, no., pp. 1799-1804 Vol.3, 14-16 Aug. 2004

[2] Atallah, K.; Howe, D., "A novel high-performance magnetic gear," Magnetics, IEEE Transactions on, vol.37, no.4, pp.28442846, Jul 2001

[3] Chau, K.T.; Dong Zhang; Jiang, J.Z.; Chunhua Liu; Yuejin Zhang, "Design of a Magnetic-Geared Outer-Rotor Permanent-Magnet Brushless Motor for Electric Vehicles," Magnetics, IEEE Transactions on, vol.43, no.6, pp.2504-2506, June 2007.

[4] Chau, K.T.; Chan, C.C.; Chunhua Liu, "Overview of PermanentMagnet Brushless Drives for Electric and Hybrid Electric Vehicles," Industrial Electronics, IEEE Transactions on, vol.55, no.6, pp.2246-2257, June 2008

[5] Jian, L.N.; Chau, K.T.; Dong Zhang; Jiang, J.Z.; Zheng Wang, "A Magnetic-Geared Outer-Rotor Permanent-Magnet Brushless Machine for Wind Power Generation," Industry Applications Conference, 2007. 42nd IAS Annual Meeting. Conference Record of the 2007 IEEE, vol., no., pp.573-580, 23-27 Sept. 2007

[6] Frank, N.W.; Toliyat, H.A., "Gearing ratios of a magnetic gear for marine applications," Electric Machines and Drives Conference, 2009. IEMDC '09. IEEE International, vol., no., pp.1224-1230, 3 6 May 2009

[7] Shah, L.; Cruden, A.; Williams, B.W., "A Magnetic Gear Box for application with a Contra-rotating Tidal Turbine," Power Electronics and Drive Systems, 2007. PEDS '07. 7th International Conference on, vol., no., pp.989-993, 27-30 Nov. 2007

[8] Atallah, K.; Howe, D., "A novel high-performance magnetic gear," Magnetics, IEEE Transactions on, vol.37, no.4, pp.28442846, Jul 2001

[9] Atallah, K.; Calverley, S.D.; Howe, D., "Design, analysis and realisation of a high-performance magnetic gear," Electric Power Applications, IEE Proceedings -, vol.151, no.2, pp. 135-143, Mar 2004

[10] Rasmussen, P.O.; Andersen, T.O.; Jorgensen, F.T.; Nielsen, O., "Development of a high-performance magnetic gear," Industry Applications, IEEE Transactions on, vol.41, no.3, pp. 764-770, May-June 2005

[11] Marquez, H.J., Nonlinear Control Systems, Hoboken, New Jersey, John Wiley and Sons, 2003 